OPEN ACCESS

Edited by:

Jorge Eugenio Vidal,

Emory University, United States

Reviewed by:

Don Thushara Galbadage,

Texas A\&M University, United States

Xueqing $W u$,

Sir Run Run Shaw Hospital, China

${ }^{*}$ Correspondence:

Da Teng

tengda@caas.cn

Huan Fan

fanhuan13212107231@126.com

Jianhua Wang

wangjianhua@caas.cn;

2681298635@qq.com

tThese authors have contributed equally to this work

Specialty section:

This article was submitted to

Bacteria and Host,

a section of the journal

Frontiers in Cellular and Infection

Microbiology

Received: 26 November 2018 Accepted: 15 February 2019

Published: 26 February 2019

Citation:

Zhao $F$, Yang $N$, Wang $X$, Mao $R$, Hao Y, Li Z, Wang $X$, Teng D, Fan $H$

and Wang J (2019) In vitro/vivo Mechanism of Action of MP1102 With

Low/Nonresistance Against

Streptococcus suis Type 2 Strain

CVCC 3928

Front. Cell. Infect. Microbiol. 9:48. doi: 10.3389/fcimb.2019.00048

\section{In vitro/vivo Mechanism of Action of MP1102 With Low/Nonresistance Against Streptococcus suis Type 2 Strain CVCC 3928}

\author{
Fei Zhao ${ }^{1,2,3+}$, Na Yang ${ }^{1,2+}$, Xiumin Wang ${ }^{1,2}$, Ruoyu Mao ${ }^{1,2}$, Ya Hao ${ }^{1,2}$, Zhanzhan Li, ${ }^{1,2}$, \\ Xiao Wang ${ }^{1,2}$, Da Teng ${ }^{1,2 *}$, Huan Fan ${ }^{3 *}$ and Jianhua Wang ${ }^{1,2 *}$ \\ ${ }^{1}$ Gene Engineering Laboratory, Feed Research Institute, Chinese Academy of Agricultural Sciences, Beijing, China, ${ }^{2}$ Key \\ Laboratory of Feed Biotechnology, Ministry of Agriculture and Rural Affairs, Beijing, China, ${ }^{3}$ Tianjin Animal Science and \\ Veterinary Research Institute, Tianjin, China
}

Streptococcosis is recognized as a leading infectious disease in the swine industry. Streptococcus suis serotype 2 is regarded as the most virulent species, which threatens human and pig health and causes serious economic losses. In this study, multiple in vitro and in vivo effects of MP1102 on multidrug resistant S. suis was studied for the first time. MP1102 exhibited significant antibacterial activity against S. suis (minimum inhibitory concentration, $\mathrm{MIC}=0.028-0.228 \mu \mathrm{M}$ ), rapid bacteriocidal action, a longer postantibiotic effect than ceftriaxone, and a synergistic or additive effect with lincomycin, penicillin, and ceftriaxone $(\mathrm{FICl}=0.29-0.96)$. No resistant mutants appeared after 30 serial passages of $S$. suis in the presence of MP1102. Flow cytometric analysis and electron microscopy observations showed that MP1102 destroyed S. suis cell membrane integrity and affected $S$. suis cell ultrastructure and membrane morphology. Specifically, a significantly wrinkled surface, intracellular content leakage, and cell lysis were noted, establishing a cyto-basis of nonresistance to this pathogen. DNA gel retardation and circular dichroism analysis indicated that MP1102 interacted with DNA by binding to DNA and changing the DNA conformation, even leading to the disappearance of the helical structure. This result further supported the mechanistic basis of nonresistance via interaction with an intracellular target, which could serve as a means of secondary injury after MP1102 is transported across the membrane. Upon treatment with 2.5-5.0 mg/kg MP1102, the survival of mice challenged with S. suis was 83.3-100\%. MP1102 decreased bacterial translocation in liver, lung, spleen, and blood; inhibited the release of interleukin- $1 \beta$ and tumor necrosis factor- $\alpha$; and relieved the lung, liver, and spleen from acute injury induced by S. suis. These results suggest that MP1102 is a potent novel antibacterial agent for the treatment of porcine streptococcal disease.

Keywords: Streptococcus suis, antimicrobial peptides, MP1102, membrane damage, DNA interference, in vivo efficacy 


\section{INTRODUCTION}

Streptococcus suis is a major porcine pathogen related to a series of serious zoonosis, including pneumonia, sepsis, meningitis, arthritis, and endocarditis, and can be transmitted to humans (Lun et al., 2007). S. suis serotype 2 is the most prevalent serotype and is the most closely associated with diseases in pigs and humans (Lun et al., 2007; Groves et al., 2015). In fact, its epidemic is very serious as a long-standing health problem worldwide. In the last decade, the number of cases reported was tripled (Zanen and Engel, 1975; Spiss et al., 1999; Hughes et al., 2009; Feng et al., 2010; Michaud et al., 2016). In particular, two large-scale outbreaks of human infections with $S$. suis disease in China in 1998 and 2005 resulted in a significant health crisis and loss (Yu et al., 2006; Feng et al., 2010). Intensive concerns worldwide, including the threat to human and animal health and significant economic loss, represent an area of wide focus to enhance the identification of effective prevention and control approaches against $S$. suis infections (Dejace et al., 2017).

At present, prevention and control measures of $S$. suis infection mainly include antibiotics and vaccines (Feng et al., 2014). Antibiotics have always played a leading role in therapy of diseases caused by $S$. suis. However, antibiotic resistance becomes increasingly serious due to antibiotic overuse and the single target nature of this class of drugs. Approximately $85 \%$ of S. suis strains are resistant to commonly used antibiotics, including macrolides, lincosamides, sulfonamides, and tetracyclines (Callens et al., 2013; Varela et al., 2013). Various types of vaccines have been developed, but their efficacy varies considerably. Immunization of pigs is hindered by the lack of an autogenous vaccine protecting against more than one serotype owing to the complexity of $S$. suis with multiple serotypes. Several proteins and factors from $S$. suis were discovered as vaccine candidates in succession, including muramidase-released protein, extracellular factor, suilysin, and immunoglobulin M-degrading enzyme. In addition, the benefits and limitations of these agents are also described (Wisselink et al., 2001; Kock et al., 2009; Seele et al., 2015; Segura, 2015). Currently, no effective commercial vaccine is available.

Therefore, effective antimicrobial agents against $S$. suis are urgently needed. Antimicrobial peptides (AMPs) have been receiving increased attention. A fungal defensin plectasin isolated from Pseudoplectania nigrella is especially active against Grampositive bacteria, especially Staphylococcus and Streptococcus (Mygind et al., 2005). MP1102, a plectasin-derived peptide, displays more potent antibacterial activity, low hemolytic activity $(0.05 \%$ hemolysis at a concentration of $128 \mu \mathrm{g} / \mathrm{ml})$ and strong in vivo bactericidal activity toward S. aureus (Zhang et al., 2015), indicating that it is a potential candidate mainline drug against bacterial infection. However, no studies have focused on the activity of MP1102 against S. suis.

From the antimicrobial susceptibility results of the disk diffusion method (Table 1) (Clinical Laboratory Standard Institute, 2014), S. suis CVCC 3928 showed resistance to neomycin, sulfisoxazole, and polymyxin B and sensitivity to cefazolin, streptomycin, tetracycline, erythromycin, azithromycin, vancomycin, chloramphenicol, norfloxacin, and penicillin. In this work, in vitro dual mechanisms of MP1102 against S. suis CVCC 3928 with significantly high antibacterial activity and low/nonresistance were elucidated for the first time; additionally, in vivo effects of MP1102 treatment were evaluated through a mouse peritonitis model induced by S. suis.

\section{MATERIALS AND METHODS}

\section{Materials}

MP1102 with the purity of $96.4 \%$ was prepared based on our previous protocols (Zhang et al., 2015) and stored at $-20^{\circ} \mathrm{C}$ before subsequent antibacterial assessments. Ceftriaxone and propidium iodide (PI) were purchased from Dalian Meilun Biological Technology Co., Ltd. and Sigma-Aldrich Shanghai Trading Co. LLC (Shanghai, China), respectively. Other reagents were of analytical grade. S. suis strains (CVCC 3928, 3309, and 606) isolated from piglets and Streptococcus pneumoniae CVCC 2350 were obtained from the China Veterinary Culture Collection (CVCC). S. pneumoniae CGMCC 1.8722 was obtained from China General Microbiological Culture Collection Center (CGMCC). Mice were purchased from Beijing Vital River Laboratory Animal Technology Co., Ltd.

\section{Determination of Minimum Inhibitory Concentration (MIC)}

The MICs of MP1102 were measured by the broth microdilution method (Yang et al., 2016). Test strains were cultured to mid-log phase at $37^{\circ} \mathrm{C}$ in Mueller-Hinton Broth medium (MHB, Beijing Aoboxing Bio-Tech Co. Ltd.) and diluted with MHB medium to $1 \times 10^{5} \mathrm{CFU} / \mathrm{ml}$. A $10-\mu$ l of serial two-fold dilutions of MP1102 or ceftriaxone and $90 \mu \mathrm{l}$ cell suspension were added to each well of 96-well microplates and then incubated at $37^{\circ} \mathrm{C}$ for $18-24 \mathrm{~h}$. The MIC was defined as the lowest concentration that prevented visible growth of bacteria. All assays were performed in triplicate.

\section{Bactericidal Kinetics Measurement}

Bacterial cells were grown to exponential-phase at $37^{\circ} \mathrm{C}$ in $\mathrm{MHB}$ medium and incubated with different concentrations of MP1102 $(1 \times, 2 \times$, and $4 \times$ MIC, respectively). Ceftriaxone and PBS were used as the positive and blank controls, respectively. The samples were incubated at $250 \mathrm{rpm}$ and $37^{\circ} \mathrm{C}$. The $100-\mu l$ samples were taken from each flask at different time intervals $(0-10 \mathrm{~h})$ and plated to count the colonies after gradient dilution with PBS (Xi et al., 2013).

\section{Membrane Permeabilization Analysis by Flow Cytometer}

S. suis strain CVCC 3928 cells were cultured to mid-log phase at $37^{\circ} \mathrm{C}$ in $\mathrm{MHB}$ medium, washed with $0.01 \mathrm{M}$ PBS buffer thrice, resuspended in the PBS buffer to $1 \times 10^{7} \mathrm{CFU} / \mathrm{ml}$ and incubated with $1 \times, 2 \times$, and $4 \times$ MIC MP 1102 at $37^{\circ} \mathrm{C}$ for 0.5 and $2 \mathrm{~h}$. The samples were detected by a FACS Calibur Flow Cytometer (BD, USA) after fixation with PI, and CellQuest Pro software (BD, USA) was used for data analysis (Zong et al., 2016). 
TABLE 1 | The susceptibility analysis of S. suis CVCC 3928 against antimicrobial.

\begin{tabular}{|c|c|c|c|c|c|c|}
\hline Antimicrobial & Disc content & $\mathrm{S}(\mathrm{mm})$ & I (mm) & $\mathbf{R}(\mathrm{mm})$ & Measured value $(\mathrm{mm})$ & Susceptibility evaluation \\
\hline Cefazolin & $30 \mu \mathrm{g}$ & $\geq 18$ & $15-17$ & $\leq 14$ & 37.5 & S \\
\hline Gentamycin & $10 \mu \mathrm{g}$ & $\geq 15$ & $13-14$ & $\leq 12$ & 14.5 & 1 \\
\hline Kanamycin & $30 \mu g$ & $\geq 18$ & $14-17$ & $\leq 13$ & 13.5 & I \\
\hline Streptomycin & $10 \mu \mathrm{g}$ & $\geq 15$ & $12-14$ & $\leq 11$ & 16.5 & $S$ \\
\hline Neomycin & $30 \mu \mathrm{g}$ & $\geq 17$ & $13-16$ & $\leq 12$ & 11.5 & $\mathrm{R}$ \\
\hline Tetracycline & $30 \mu g$ & $\geq 23$ & 19-22 & $\leq 18$ & 26 & S \\
\hline Erythromycin & $15 \mu \mathrm{g}$ & $\geq 21$ & $16-20$ & $\leq 15$ & 26.5 & $S$ \\
\hline Azithromycin & $15 \mu \mathrm{g}$ & $\geq 18$ & $14-17$ & $\leq 13$ & 24.5 & S \\
\hline Vancomycin & $30 \mu \mathrm{g}$ & $\geq 17$ & & & 22.5 & S \\
\hline Polymyxin B & $300 \mathrm{IU}$ & $\geq 12$ & $9-11$ & $\leq 8$ & 0 & $\mathrm{R}$ \\
\hline Chloramphenicol & $30 \mu \mathrm{g}$ & $\geq 18$ & $13-17$ & $\leq 12$ & 28 & S \\
\hline Bacitracin & $0.04 U$ & $\geq 13$ & $9-12$ & $\leq 8$ & 11.5 & 1 \\
\hline Sulfisoxazole & $300 \mu \mathrm{g}$ & $\geq 19$ & $16-18$ & $\leq 15$ & 14.5 & $\mathrm{R}$ \\
\hline Norfloxacin & $10 \mu g$ & $\geq 17$ & $13-16$ & $\leq 12$ & 20.5 & S \\
\hline Penicillin & $10 U$ & $\geq 28$ & $20-27$ & $\leq 19$ & 36.5 & S \\
\hline
\end{tabular}

$R$, resistant; I, intermediate; S, sensitive.

\section{Resistance to MP1102}

Resistance to MP1102 and antibiotics (ceftriaxone, penicillin, and lincomycin) was assessed by the MIC assays. A mid-log phase culture of S. suis $\left(1 \times 10^{5} \mathrm{CFU} / \mathrm{ml}\right)(90 \mu \mathrm{l} /$ well $)$ was added into 96-well plates. Solutions of MP1102 or antibiotics $(10 \mu \mathrm{l})$ were added into plates at concentrations of $8 \times, 4 \times, 2 \times, 1 \times$, $0.5 \times, 0.25 \times, 0.125 \times$, and $0.0625 \times$ MIC. After $18 \mathrm{~h}$ incubation at $37^{\circ} \mathrm{C}$ under continuous shaking at each passage, cells from the second highest concentration showing visible growth were used to inoculate the subsequent culture. The serial passaging was repeated for $30 \mathrm{~d}$ (Mah et al., 2003; Li et al., 2017).

\section{The Postantibiotic Effect (PAE) of MP1102 Against S. suis}

After treatment with MP1102 or ceftriaxone sodium $(1 \times, 2 \times$, and $4 \times$ MIC) for $2 \mathrm{~h}$, S. suis cells $\left(10^{7} \mathrm{CFU} / \mathrm{ml}\right)$ were diluted 1,000 times by medium, transferred to new flasks and incubated at $37^{\circ} \mathrm{C}$ and $250 \mathrm{rpm}$. The samples were taken from flasks for counting every hour until bacterial cultures become turbid. Untreated bacteria were used as controls. The PAE was calculated using the equation: $\mathrm{PAE}=\mathrm{T}-\mathrm{C}$, where $\mathrm{T}$ is time $(\mathrm{h})$ required for the $\mathrm{CFU}$ in the test culture to increase by 10 times above the count immediately after dilution and $\mathrm{C}$ is the corresponding time (h) for the control (Li et al., 2017).

\section{Synergism Test}

The checkerboard microtiter assay was applied for determining the interaction of combinations of MP1102 with ceftriaxone, penicillin, lincomycin, kanamycin, and gentamicin, separately (Zong et al., 2016). MP1102 and antibiotics were dispensed into 96-well cell culture plates at final concentrations ranging from $1 / 8$ to $8 \times$ MIC in each well. The MIC values were determined as the MIC assay described above. The effects of combination were evaluated by calculating the fractional inhibitory concentration index (FICI) of each combination. The synergistic experiments were performed in triplicate. The FICI represents the sum of the FICs of each drug tested, where the FIC is defined as the MIC of each drug when used in combination divided by the MIC of the drug when used alone. FICI $=($ MICdrug $\mathrm{A}$ in combination/MICdrug $\mathrm{A}$ alone $)+$ (MICdrug B in combination/MICdrug B alone).

\section{Transmission Electron Microscope (TEM) Observations}

The mid-logarithmic S. suis CVCC 3928 cells $\left(1 \times 10^{8} \mathrm{CFU} / \mathrm{ml}\right)$ and $4 \times$ MIC MP1102 were incubated at $37^{\circ} \mathrm{C}$ for $2 \mathrm{~h}$. The cells were fixed in $2.5 \%$ (w/v) glutaraldehyde; postfixed in $1 \%$ osmium tetroxide $\left(\mathrm{OsO}_{4}\right)$; dehydrated with an ethanol series of 50, 70, 85,95 , and $100 \%$ ( $15 \mathrm{~min} /$ time); and transferred to epoxy resins (Wang et al., 2017). The cells were stained with $1 \%$ uranium acetate and observed with a TEM (JEM1400, Japan).

\section{Scanning Electron Microscopy (SEM) Observations}

The mid-logarithmic S. suis CVCC 3928 cells $\left(1 \times 10^{8} \mathrm{CFU} / \mathrm{ml}\right)$ and $4 \times$ MIC MP1102 were incubated at $37^{\circ} \mathrm{C}$ for $2 \mathrm{~h}$. The cells were fixed with $1 \% \mathrm{OsO}_{4}$, dehydrated by ethanol series (50,70,85, 95, and $100 \%)$ and dried by $\mathrm{CO}_{2}$ according to the previous study (Zong et al., 2016). After platinum coating, the samples were observed with a QUANTA200 SEM (FEI, Philips, Netherlands).

\section{Interaction of MP1102 With the Genomic DNA From S. suis}

The gel retardation assay was performed to observe the binding of MP1102 to S. suis genomic DNA. Genomic DNA was extracted from S. suis strain CVCC 3928 using a bacterial DNA kit (TIANGEN Biotech Co., Ltd., Beijing). MP1102 was dissolved and serially diluted with DNA-binding buffer. The samples containing MP1102 and genomic DNA $(0.5 \mu \mathrm{g})$ in 
$20 \mu 1$ DNA binding buffer at peptide/DNA ratios ranging from 0.5 to $10.0(\mathrm{w} / \mathrm{w})$ were mixed at $37^{\circ} \mathrm{C}$ for $10 \mathrm{~min}$. Genomic DNA was photographed using a Geliance 200 imaging system (PerkinElmer, USA) after electrophoresis (Hao et al., 2017).

Circular dichroism (CD) spectra were performed to examine whether MP1102-DNA binding affects the secondary structure of the genomic DNA from S. suis CVCC 3928. After the incubation of MP1102 and genomic DNA at mass ratios of $0,0.5$, and 10.0 for $10 \mathrm{~min}$ at room temperature, the mixtures were loaded into a cuvette of $1.0-\mathrm{mm}$ path length and scanned from 220 to $300 \mathrm{~nm}$ at $25^{\circ} \mathrm{C}$ using a Pistar $\pi-180 \mathrm{CD}$ spectrometer (Applied Photophysics Ltd., UK) (Zong et al., 2016).

\section{Mouse in vivo Experiments}

The S. suis infection protocol was performed as previously described (Jiao et al., 2017). The Institute for Cancer Research (ICR) female mice (6-week-old) (ten mice/group) were intraperitoneally injected with $1.0 \mathrm{ml}$ of S. suis CVCC 3928 (7.5 $\times 10^{8} \mathrm{CFU} / \mathrm{ml}$ ) and given two doses of MP1102 (2.5 and 5.0 $\mathrm{mg} / \mathrm{kg}$ of body weight) or ceftriaxone $(7.5$ and $15.0 \mathrm{mg} / \mathrm{kg}$ of body weight) after $2 \mathrm{~h}$ postinfection. Mice injected with only $S$. suis CVCC 3928 or PBS served as negative or blank controls, respectively. Survival rates of mice were monitored daily for $7 \mathrm{~d}$.

To assay bacterial loads in organs, the lungs, livers, and spleens were removed from the mice sacrificed at $24 \mathrm{~h}$ posttreatment and homogenized in sterile PBS for S. suis CVCC 3928 colony counting. Each group was repeated with five mice.

Serum was separated from mice $4 \mathrm{~h}$ posttreatment. The levels of cytokines (IL-1 $\beta$, IL-10, and TNF- $\alpha$ ) in serum were detected using an enzyme-linked immunosorbent assay (ELISA) kit from Jiaxuan Biotech Co., Ltd. (Beijing) (Wang et al., 2017). Each group was repeated with nine mice that were randomly subdivided into three groups for cytokines assay.

The mice were sacrificed 1 and $7 \mathrm{~d}$ posttreatment, and the lungs, livers and spleens were removed and fixed in $4 \%$ paraformaldehyde for $1 \mathrm{~d}$. The organs were infiltrated with xylene and embedded in paraffin. Then, samples were sectioned and stained with hematoxylin eosin (HE). The tissue samples were observed using a light microscope (BX51, Olympus Optical Company, Japan). Subsequently, the degree of inflammation of tissues was graded in Beijing Jialanhai Biotech Co., Ltd. (Knodell et al., 1981; Rotta et al., 1999).

\section{Significance Analysis}

The data were conducted using ANOVA with software SAS 9.2 (SAS Institute Inc., USA). The $P<0.05, P<0.01$, and $P<0.001$ were defined as statistically significant, highly significant, and very highly significant, respectively.

\section{Ethics Statement}

All animal procedures used in this study were approved by the Animal Care and Use Committee of Feed Research Institute, Chinese Academy of Agricultural Sciences (Permit Number: 20150309) and were performed in accordance with ARRIVE (Animals in Research: Reporting in vivo Experiments) guidelines (Kilkenny et al., 2010).

\section{RESULTS}

\section{MP1102 Exhibits Potent Antibacterial Activity Against $S$. suis}

The antibacterial activity of MP1102 and ceftriaxone against the Streptococcus was listed in Table 2. The MICs of MP1102 against the test $S$. suis strains were from 0.028 to $0.228 \mu \mathrm{M}$, and those of ceftriaxone were 0.048 and $0.201 \mu \mathrm{M}$. For $S$. pneumoniae CGMCC 1.8722 and CVCC 2350, the MICs of MP1102 were $0.228 \mu \mathrm{M}$, however, ceftriaxone did not display obvious antibacterial activity against the test $S$. pneumoniae strains $(\mathrm{MIC}>25.723 \mu \mathrm{M})$.

\section{MP1102 Effectively Kills S. suis}

As shown in Figure 1A, the $S$. suis cells counts $\left(\log _{10} \mathrm{CFU} / \mathrm{ml}\right)$ in the control group reached to 8.59 at $6 \mathrm{~h}$ and remained at a steady level from 8 to $24 \mathrm{~h}$. For the MP1102 treatment groups, the cell counts decreased to complete sterilization in $6-8 \mathrm{~h}$ in a dose-independent manner, and no colonies were regrown even at $1 \times$ MIC MP1102. However, the bacterial counts in the $2 \times$ MIC ceftriaxone group showed slow reduction to complete sterilization until $24 \mathrm{~h}$.

\section{Delayed Drug Resistance}

Long-term and repeated exposures of microorganisms to subinhibitory doses of antibiotics promote acquisition of drug resistance (Hodges et al., 1992). To investigate whether MP1102 could adequately prevent drug resistance development, S. suis CVCC 3928 exposed to sub-MIC peptides were passaged daily and used for determination of MIC values for up to 30 passages. Various classes of clinically used antibiotics, including ceftriaxone, lincomycin, and penicillin, were used as controls in this study. As shown in Figure 1B, development of resistance was not observed in $S$. suis during continuous serial passaging in the presence of sub-MIC of MP1102 over $30 \mathrm{~d}$. In contrast, $S$. suis rapidly developed resistance to lincomycin within $2 \mathrm{~d}$ of exposure. Additionally, resistance of ceftriaxone and penicillin increased by 2 -fold on the second and 24 th $\mathrm{d}$.

\section{PAE of MP1102 in S. suis}

The results of a dose-independent PAE of MP1102 or ceftriaxone against S. suis CVCC 3928 are shown in Figure 1C. The PAE values of MP1102 to $S$. suis were $0.76,1.75$, and $2.92 \mathrm{~h}$ at $1 \times, 2 \times$, and $4 \times$ MIC, respectively. The PAE values of ceftriaxone to $S$. suis

TABLE 2 | Minimum inhibitory concentrations (MICs) assay.

\begin{tabular}{lcc}
\hline Strains & MP1102 $(\boldsymbol{\mu} \mathbf{M})$ & $\begin{array}{c}\text { Ceftriaxone sodium } \\
(\boldsymbol{\mu} \mathbf{M})\end{array}$ \\
\hline $\begin{array}{l}\text { Streptococcus suis CVCC } \\
3928\end{array}$ & 0.028 & 0.048 \\
S. suis CVCC 3309 & 0.028 & 0.096 \\
S. suis CVCC 606 & 0.228 & 0.201 \\
Streptococcus pneumoniae & 0.228 & $>25.723$ \\
CGMCC 1.8722 & & $>25.723$ \\
S. pneumoniae CVCC 2350 & 0.228 &
\end{tabular}


A

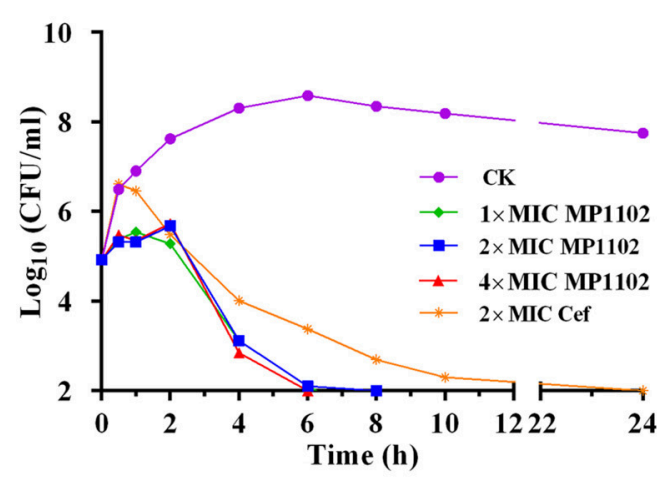

C

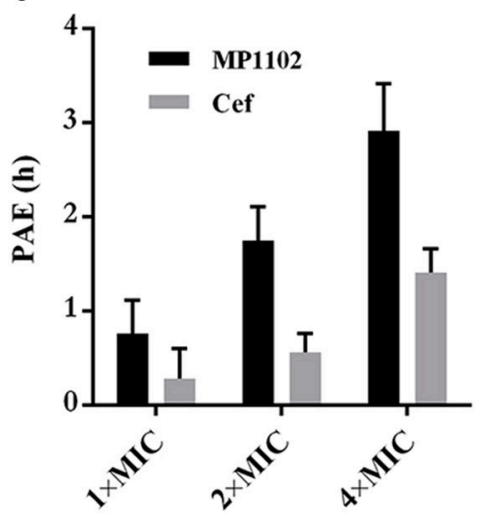

D

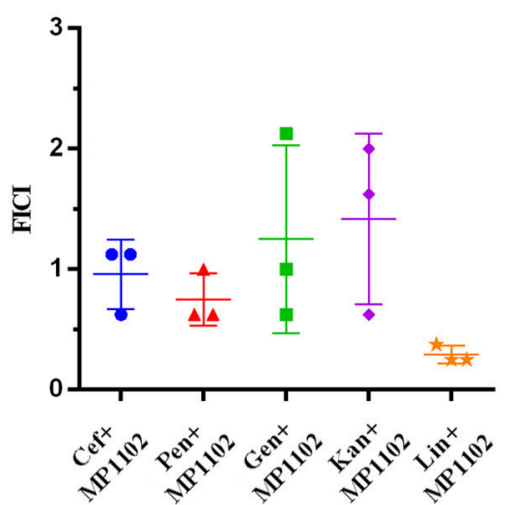

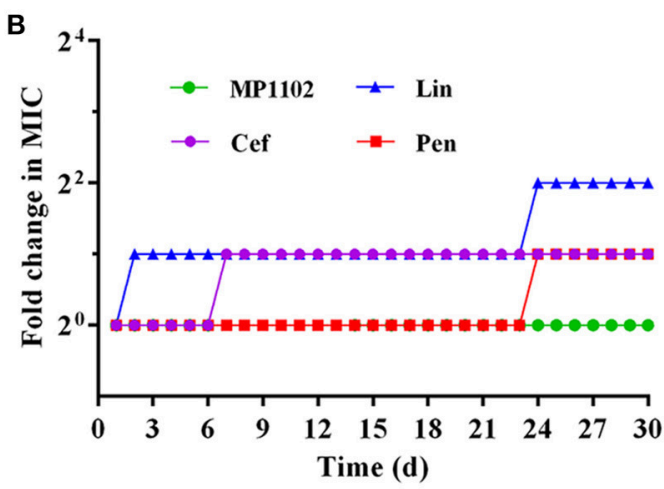

E

FIGURE 1 | Bactericidal kinetics and flow cytometric analysis of MP1102. (A) Bactericidal kinetics assay of S. suis CVCC 3928 treated with MP1102. (B) Resistance of MP1102 and antibiotics; (C) PAE of MP1102 or ceftriaxone (Cef) (1×, 2x, and 4× MIC); (D) Synergism test of MP1102 and antibiotics (Cef, ceftriaxone; Pen, penicillin; Lin, lincomycin; Kan, kanamycin; Gen, gentamicin); (E) Flow cytometric analysis of membrane permeabilization. After treatment with 1×, 2x, and 4x MIC MP1102 for 2 h, S. suis CVCC 3928 cells were stained with PI and analyzed by flow cytometry.

were $0.28,0.56$, and $1.41 \mathrm{~h}$ at $1 \times, 2 \times$, and $4 \times$ MIC, respectively. The results indicated a dose-dependent PAE with MP1102 and ceftriaxone against S. suis, and the PAEs of ceftriaxone were reduced compared with those of MP1102.

\section{Synergism Assays}

The efficacy of interactions between MP1102 and traditional antibiotics against S. suis CVCC 3928 is shown in Figure 1D. Combination between MP1102 and lincomycin showed a synergistic effect with FICI of 0.29 . The FICI between MP1102 and ceftriaxone $($ FICI $=0.96)$ and penicillin $($ FICI $=0.75)$ showed an additive effect. In addition, kanamycin and gentamicin showed no effect with FICI indexes of 1.25 and 1.42. Antagonism was not detected.

\section{MP1102 Destroyed S. suis Cell Membrane Integrity}

PI can intercalate into nucleic acids after penetrating the damaged cell membrane. Therefore, PI was used as an indicator to assay the effects of MP1102 on S. suis cell plasma membrane by flow cytometry (Xi et al., 2014). Figure 1E shows that the percentages of PI-permeable S. suis cells after treatment with $1 \times, 2 \times$, and $4 \times$ MIC MP1102 for $2 \mathrm{~h}$ were $34.9,35.1$, and $58.2 \%$, respectively. However, in the absence of MP1102, the percentage of PI influx into the $S$. suis cells was $1.24 \%$, suggesting that $S$. suis cell membranes were intact. These results indicated that MP1102 disrupted cell membrane with penetrating action in a concentrationdependent manner.

\section{MP1102 Affected S. suis Cell Ultrastructure and Membrane Morphology}

The effect of MP1102 on cell integrity and morphology of $S$. suis was directly visualized under SEM and TEM observations. SEM observations showed that $S$. suis cells exhibited serious cell damage after treatment with MP1102, such as deep wrinkles on the cell surface, intracellular content leakage and cell lysis (Figure 2A), compared with intact cells not treated with peptide. MP1102-treated S. suis cells exhibited heterogeneous electron density in the cytoplasm, an incomplete plasma membrane, and plasmolysis under TEM observations (Figure 2B). Together with the above results of bacterial plasma membrane permeabilization, these results further confirmed that MP1102 damage S. suis cell membranes. 

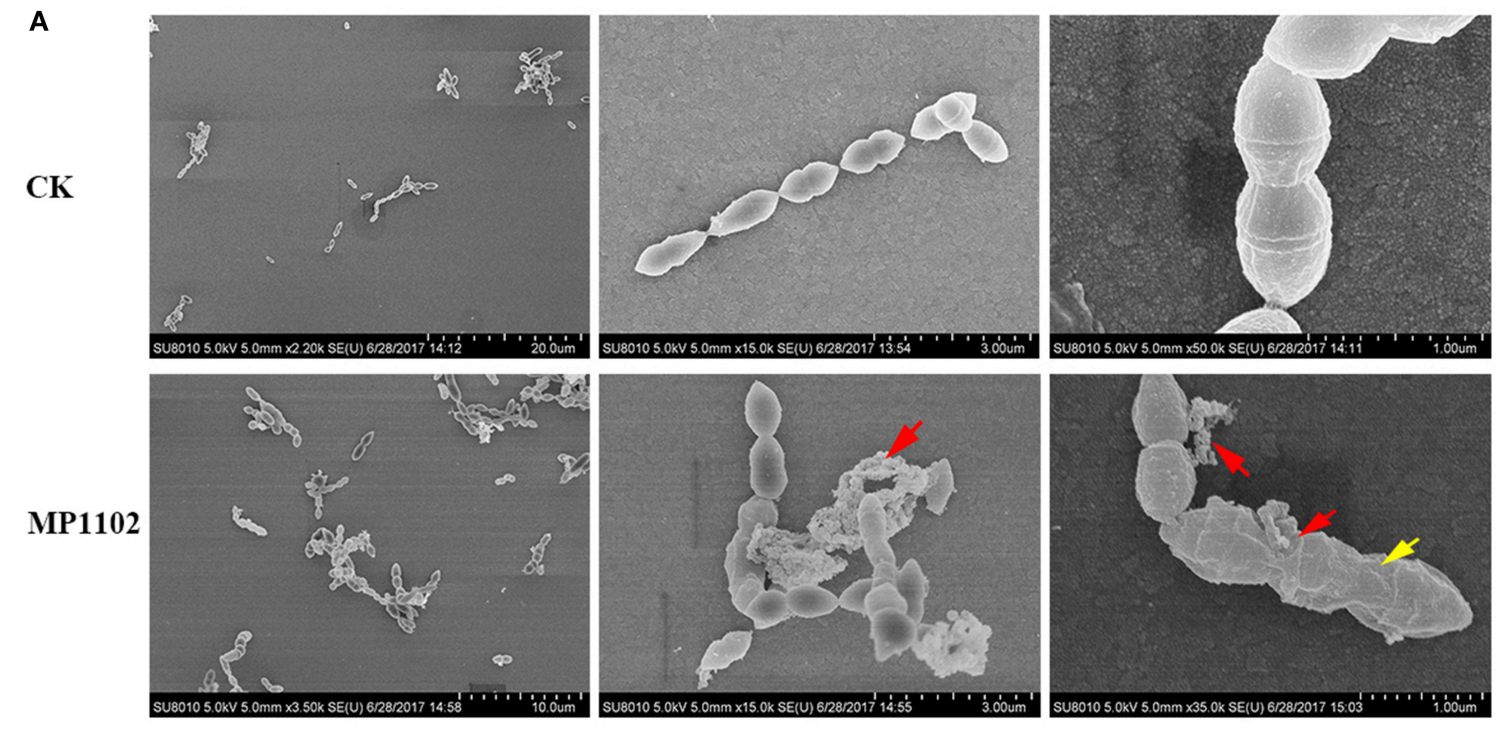

B

CK
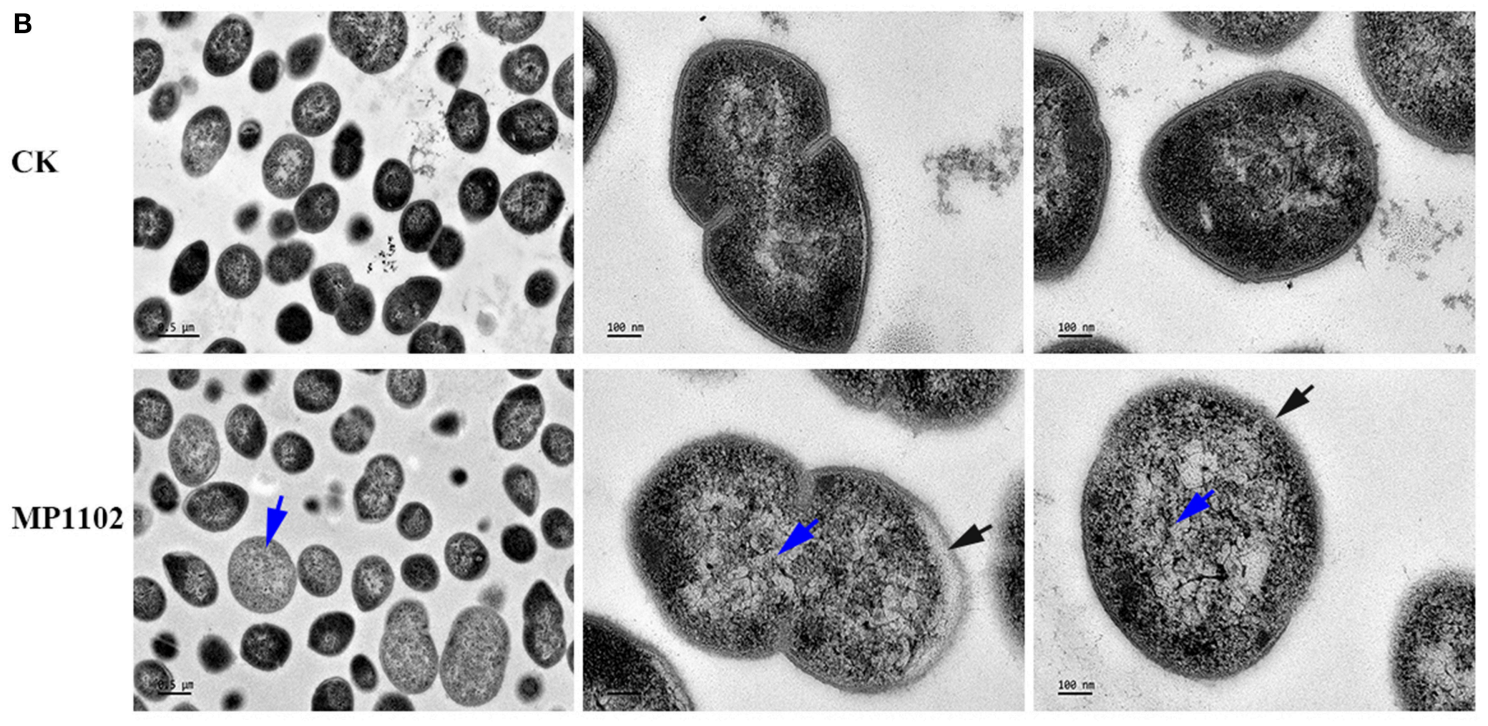

FIGURE 2 | Effects of MP1102 on the cell morphology and ultrastructure of S. suis strain CVCC 3928. Bacteria in mid-logarithmic growth were treated with peptides at $4 \times$ MIC for 2 h. (A) SEM observations. (B) TEM observations. Red arrows: intracellular content leakage and cell lysis; Yellow arrows: deep wrinkles on cell surface; Blue arrows: heterogeneous electron density in cytoplasm; Black arrows: incomplete plasma membrane and plasmolysis.

\section{MP1102 Changed the S. suis Genomic DNA Conformation by DNA-Binding}

The DNA-binding ability of MP1102 was evaluated by DNA gel retardation assay to identify potential targets in cells. As shown in Figure 3, MP1102 started to prevent the migration of genomic DNA from S. suis CVCC 3928 at the peptide/DNA mass ratio of 0.5 . The DNA-binding activity of MP1102 was enhanced as the peptide mass increased. When the mass ratios reached up to 10.0, almost complete retardation of the genomic DNA was observed.

$\mathrm{CD}$ assays were performed for further confirmation of the DNA-binding affinity of MP1102. In Figure 3B, the CD spectra of S. suis genomic DNA showed a positive band and a negative band at $\sim 270$ and $245 \mathrm{~nm}$, respectively. However, dramatic changes occurred after treatment with MP1102. The elliptic intensity of the positive band declined as the peptide content increased, suggesting the insertion of MP1102 into base pairs weakened stacking interaction. In addition, the lack of a negative band demonstrated the disappearance of the helical structure when the peptide to DNA mass ratio reached 10.

\section{MP1102 Protected Mice From S. suis Infections \\ Protection of Mice Against a Lethal \\ Bacterial Challenge}

Mice without treatment were dead within $12 \mathrm{~h}$ after intraperitoneal inoculation with S. suis CVCC 3928. In the 

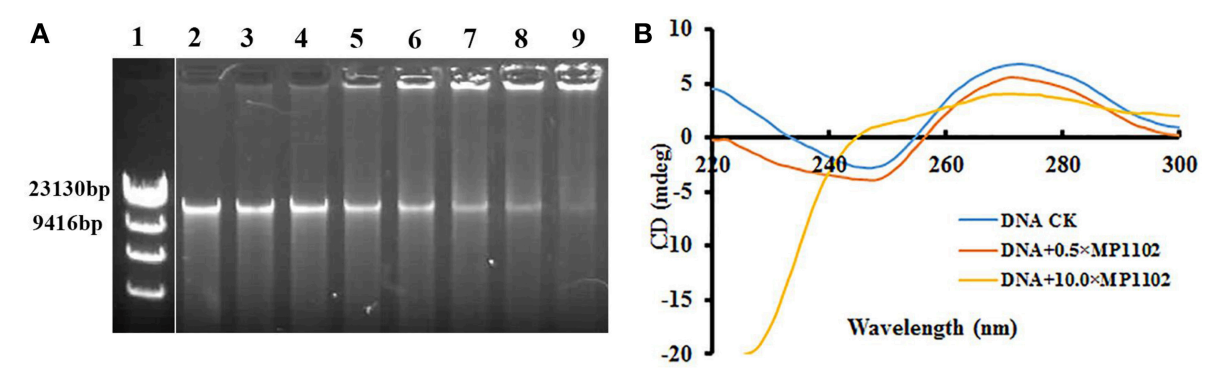

FIGURE 3 | In vitro binding of MP1102 to the S. suis strain CVCC 3928 genomic DNA. (A) Gel retardation analysis of the binding of MP1102 to genomic DNA. Line 1: DNA maker $\lambda$ DNA/HindIII; Lines 2-9: the mass ratios of MP1102 and genomic DNA were 0, 0.5, 1.0, 2.0, 4.0, 6.0, 8.0, and 10.0, respectively. (B) CD spectra analysis of genomic DNA. The mass ratios of MP1102 and genomic DNA were 0, 0.5, and 10.0, respectively.

positive control group, the survival rates of mice treated with 7.5 and $15.0 \mathrm{mg} / \mathrm{kg}$ ceftriaxone were both $50 \%$ (Figure 4A). After treatment with 2.5 and $5.0 \mathrm{mg} / \mathrm{kg}$ MP1102, the survival rates of mice were 83.3 and $100 \%$, respectively (Figure $\mathbf{4 A}$ ), which is higher than that of ceftriaxone. These results suggested that MP1102 could protect mice from a lethal S. suis challenge.

\section{Inhibition of Bacterial Translocation}

At the start of therapy, S. suis CVCC 3928 cell counts in the liver, lung, spleen, and blood were 9.14, 9.01, 9.19, and $7.60 \log _{10}$ $\mathrm{CFU} / \mathrm{g}$, respectively (Figure 4B). After treatment with $5.0 \mathrm{mg} / \mathrm{kg}$ MP1102 for $24 \mathrm{~h}$, the bacterial counts in mice liver, lung, spleen, and blood were all reduced significantly by $4.76,3.15,2.89$, and $3.50 \log _{10} \mathrm{CFU} / \mathrm{g}$, respectively, compared with untreated mice (Figure 4B). Compared with ceftriaxone $(7.5$ and $15.0 \mathrm{mg} / \mathrm{kg}$ ) and MP1102 (5.0 mg/kg), $5.0 \mathrm{mg} / \mathrm{kg}$ MP1102 more effectively reduced the bacterial burden; approximately $99.99 \%$ of $S$. suis cells were killed in liver, lung, spleen, and blood.

\section{Inhibition of Proinflammatory Cytokines}

To verify whether the protective effect of MP1102 was related to inflammatory cytokines, serum levels of IL- $1 \beta$, IL-10, and TNF$\alpha$ in mice infected with S. suis were measured. IL-1 $\beta$, IL-10, and TNF- $\alpha$ levels in infected mice treated with $2.5 \mathrm{mg} / \mathrm{kg}$ MP1102 were $60.60,1193.82$, and $365.21 \mathrm{pg} / \mathrm{ml}$, respectively, and those of $5.0 \mathrm{mg} / \mathrm{kg}$ MP1102 were $68.81,1631.09$, and $677.90 \mathrm{pg} / \mathrm{ml}$, respectively. These levels were obviously lower than those from the PBS group (152.92, 2206.35, and $3118.90 \mathrm{pg} / \mathrm{ml}$, respectively) and $15.0 \mathrm{mg} / \mathrm{kg}$ ceftriaxone group $(139.43,2848.03$, and 2355.10 $\mathrm{pg} / \mathrm{ml}$, respectively). This result indicated that MP1102 inhibited the secretion of proinflammatory cytokines TNF- $\alpha$ and IL$1 \beta$ as well as the production of anti-inflammatory cytokine IL-10 (Figure 4C).

\section{Suppression of Acute Lung, Liver, and Spleen Injury}

In the liver tissue, compared with the uninfected group (Figure 5), the morphology of hepatocytes in the untreated (PBS treated) group was irregular. In addition, $>33 \%$ vacuolar degeneration was noted around the hepatic duct area, and inflammatory cells infiltrated in the hepatic sinusoid space (Figure 5) with an inflammatory degree of 3 (Table 3). After MP1102 treatment for $1 \mathrm{~d}$, inflammation did not decrease obviously (Figure 5). After $7 \mathrm{~d}$, inflammatory symptoms were significantly reduced, a small number of inflammatory cells infiltrated (Figure 5), and the inflammation degree was between 1 and 2 (very slight) (Table 3). For the ceftriaxone group, the surviving mice showed consistent therapeutic effects, and the scores of inflammation degree were minor (1) at $1 \mathrm{~d}$ and very slight (1-2) at $7 \mathrm{~d}$.

Compared with the uninfected group, diffuse infiltration of inflammatory cells in was noted in interstitial tissue of lung in the untreated (PBS treated) group (Figure 5). In addition, inflammation was noted in bronchi and perivascular areas, and narrowing of alveolar cavity was obvious with the inflammatory scores of 3 (very serious) (Table 2). After treatment with 5.0 $\mathrm{mg} / \mathrm{kg}$ MP1102 for $1 \mathrm{~d}$, the interstitial tissue of lung tissue was infiltrated by inflammatory cells with a slight widening of the interval and relatively normal alveolar structure (Figure 5). Inflammation degree scores (1) were minor. After $7 \mathrm{~d}$, only a small amount of interstitial lung tissue was found scattered in the inflammatory cells, and the alveoli and the alveolar septum tended to be normal (Figure 5); Slight inflammation (degree 12) was noted. Ceftriaxone exhibited poor therapeutic efficacy in surviving mice. The score was serious (degree 3 ) at $1 \mathrm{~d}$ and minor (degree 1) at $7 \mathrm{~d}$ (Figure 5 and Table 3).

In the spleen tissue, compared with the normal spleen, the germinal center was obvious in the PBS group, and the edge band was clearly visible and obviously enlarged (Figure 5). Inflammation in the body was very serious (degree 3) (Table 3). After treatment with MP1102 for $1 \mathrm{~d}$, the inflammatory reaction was not reduced (Figure 5), and the scores of inflammation degree were minor (degree 1) (Table 3). The splenic nodule was slightly enlarged, and the marginal area was unclear, indicating that the inflammation disappeared after $7 \mathrm{~d}$ of treatment (Figure 5), and the inflammation degree scores were very slight (degree 1-2). Surviving mice in the ceftriaxone treatment group showed a poor therapeutic effect, as demonstrated by the inflammation degree score of 2 (serious) at $1 \mathrm{~d}$ and 1 (minor) at $7 \mathrm{~d}$ (Figure 5 and Table 3).

These data and observations indicated that MP1102 could protect mice from S. suis infections in vivo.

\section{DISCUSSION}

Inappropriate antibiotic use is a major trigger of multidrugresistant $S$. suis strain emergence, which increased treatment 

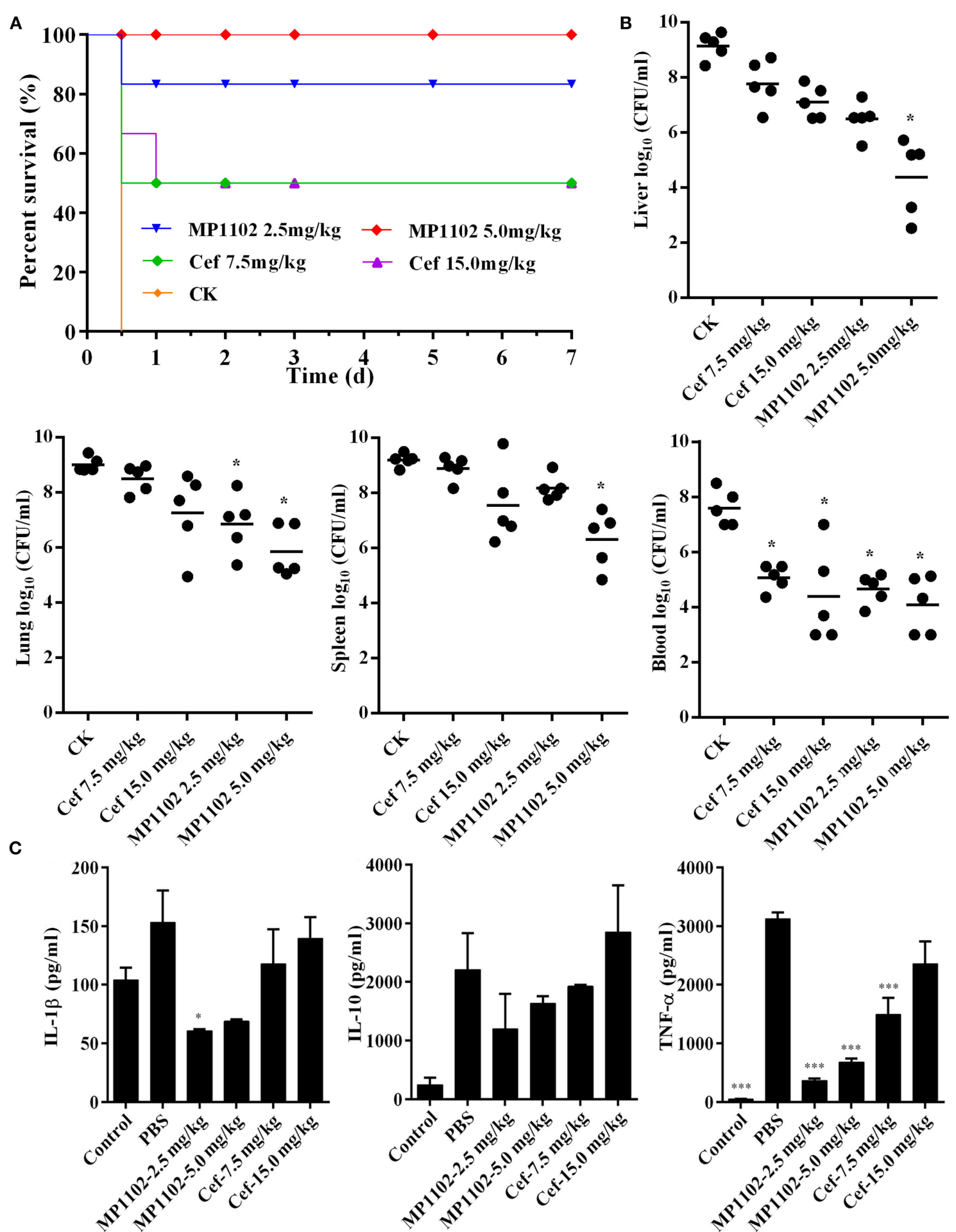

FIGURE 4 | In vivo efficacy of MP1102 on S. suis infection mice. Mice were infected intraperitoneally with S. suis CVCC 3928 (7.5 $\times 10^{8}$ CFU/ml) and treated intraperitoneally with MP1102 and ceftriaxone at $2 \mathrm{~h}$ after postinfection. (A) Survival of mice. Survival of mice was recorded for seven days. (B) Effect of MP1102 on bacterial loads in liver, lung, spleen, and blood of $S$. suis-infected mice. Lungs and livers were removed at $1 \mathrm{~d}$ posttreatment to analyze bacterial translocation. Data are expressed as the mean \pm standard deviation. ${ }^{*} p<0.01$. (C) Effects of MP1102 on sera cytokines. Sera were collected and cytokines were detected at $6 \mathrm{~h}$ after treatment. Ceftriaxone and PBS served as positive and negative controls, respectively. ${ }^{\star * *} p<0.001$. 


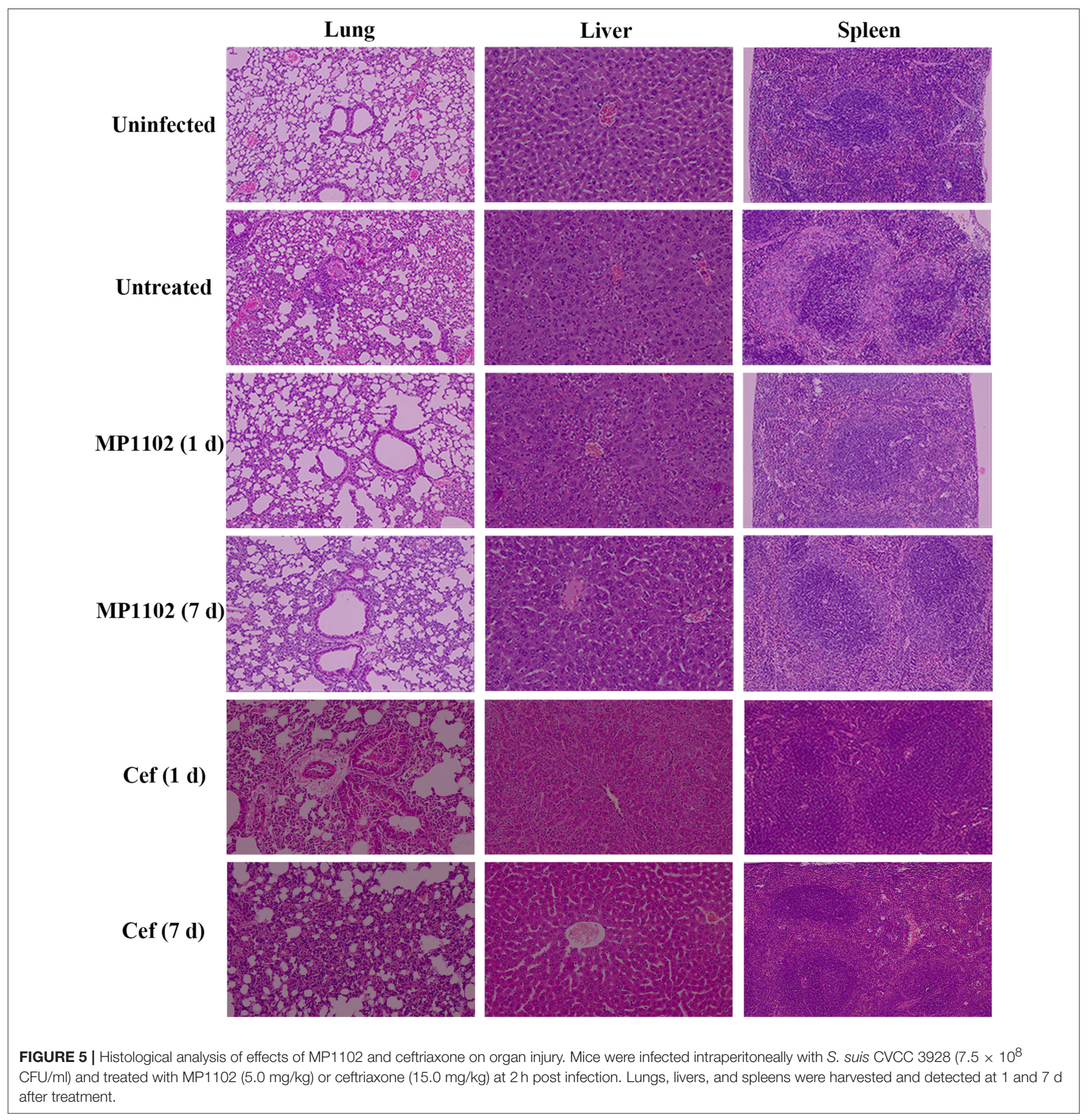

difficulty and complexity. AMPs, as novel antimicrobial compounds, have been proposed and widely accepted in medical application. Plectasin and its derived peptides have potential activity against Staphylococcus and Streptococcus, especially against some strains resistant to vancomycin and penicillin (Andes et al., 2009; Ostergaard et al., 2009; Brinch et al., 2010; Xiong et al., 2011). MP1102 showed 8-fold higher antibacterial activity against $S$. suis than that of plectasin (MIC: $0.454 \mu \mathrm{M}$ ) and similar levels to that of NZ2114 (MIC: $0.028-0.057 \mu \mathrm{M}$ )

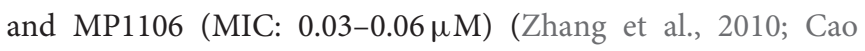
et al., 2015; Jiao et al., 2015) (Table 2). The antibacterial activity of MP1102 was only tested against only three S. suis strains, and other clinical isolates may or may not be susceptible to MP1102. S. pneumoniae is an important human pathogen that causes pneumonia, meningitis, bacteremia, and acute otitis media in both children and adults worldwide (van der Poll and Opal, 2009; Lynch and Zhanel, 2010); In particularly, it is also likely represents a new potential zoonotic pathogen in 
TABLE 3 | Degree of inflammation (score) of tissue sections.

\begin{tabular}{|c|c|c|c|c|c|c|}
\hline \multirow[t]{2}{*}{ Organs } & \multirow{2}{*}{$\begin{array}{c}\begin{array}{c}\text { Blank } \\
\text { control }\end{array} \\
1 \text { d }\end{array}$} & \multirow{2}{*}{$\begin{array}{c}\text { Negative } \\
\text { control } \\
1 \text { d }\end{array}$} & \multicolumn{2}{|c|}{ MP1102 } & \multicolumn{2}{|c|}{$\begin{array}{l}\text { Ceftriaxone } \\
\text { sodium }\end{array}$} \\
\hline & & & $1 \mathrm{~d}$ & $7 d$ & $1 \mathrm{~d}$ & $7 d$ \\
\hline Liver & 0 & 3 & 1 & 0 & 1 & 0 \\
\hline Lung & 0 & 3 & 1 & 1 & 2 & 1 \\
\hline Spleen & 0 & 3 & 1 & $1-2$ & 2 & 1 \\
\hline
\end{tabular}

Mice were infected intraperitoneally with S. suis CVCC $3928\left(7.5 \times 10^{8} \mathrm{CFU} / \mathrm{ml}\right)$ and treated with MP1102 $(5.0 \mathrm{mg} / \mathrm{kg})$ and ceftriaxone $(15.0 \mathrm{mg} / \mathrm{kg})$ at $2 \mathrm{~h}$ post infection, respectively. Lungs, livers, and spleens were harvested and detected at $1 d$ and $7 d$ after treatment. Inflammatory degrees were evaluated from 3 to 0 grades (3, very serious; 2 , serious; 1-2: very slight; 1, minor; 0, no inflammation phenomenon).

companion animals and horses as newly reported (Ginders et al., 2017). In addition, antimicrobial resistance of S. pneumoniae has dramatically escalated over the past three decades (Lynch and Zhanel, 2010). Based on the strong antibacterial activity of MP1102 against $S$. pneumoniae ( $\mathrm{MIC}=0.228 \mu \mathrm{M}$, Table 2), the details of its special relationship with S. pneumoniae should be assessed in future work. MP1102 can completely kill S. suis CVCC 3928 cells within 6-8 h, and no colonies were recovered even at $1 \times$ MIC (Figure 1A). Compared with other plectasinderived peptides, MP1102 showed a superior bactericidal effect. For example, the regrowth of $S$. suis appeared after treatment with NZ2114 at $1 \times$ and $2 \times$ MIC for 3-4h (Jiao et al., 2017), and the bacterial counts decreased $1.68 \log _{10} \mathrm{CFU} / \mathrm{ml}$ even at $16 \times$ MIC MP1106 during $6 \mathrm{~h}$ and then exhibited regrowth (Jiao et al., 2015). In our previous study, the toxicity of MP1102 in human erythrocytes was $<0.05 \%$ hemolytic activity at $128 \mu \mathrm{g} / \mathrm{ml}$ (Zhang et al., 2015). Given its high bactericidal efficiency and low toxicity, MP1102 preliminarily demonstrated potential use in internal medicine.

A report from Thailand showed that a S. suis serotype 2 strain isolated from the peritoneal fluid of a $S$. suis peritonitis patient was resistant to most antibiotics, including penicillin, but was susceptible to vancomycin (Vilaichone et al., 2000). It appears enigmatic that microbes rarely develop highlevel AMP-resistance mechanisms similar to those that render many therapeutic antibiotics inefficient after short periods of application (Sahl and Shai, 2015). In our study, repeated treatment of S. suis CVCC 3928 with sub-MIC MP1102 did not induce the development of drug resistance. However, the MIC for ceftriaxone and penicillin increased by 2 -fold, and resistance to lincomycin exhibited a 4 -fold increase over the $30 \mathrm{~d}$ duration (Figure 1B). Remarkably, ceftriaxone, penicillin, and lincomycin are common antibiotics that have been used for many years in clinical; therefore, whether the characteristic of not easy to produce resistance of MP1102 can stand the test of time needs further studies.

PAE, as an important pharmacodynamic parameter, should be considered in the selection of antibiotic dosing regimens in clinical use. In this study, the PAE of $1 \times, 2 \times$, and $4 \times$ MIC MP1102 to S. suis CVCC 3928 were 2.714, 3.125, and 2.071 times increased compared with ceftriaxone (Figure 1C). A long PAE of MP1102 might contribute to lower dose, longer interval of administration, and thus potentially lower treatment cost, drug exposure, and drug resistance (Osterberg and Blaschke, 2005).

Combination therapies have distinct advantages over monotherapies in terms of their broad spectrum and synergistic effect, which directly leads to reduced dosage and indirectly leads to the delay of antibiotic resistance. Upadhyay et al. reported that a combination of ampicillin and azithromycin improved effectiveness in a murine Group B Streptococcus (GBS) sepsis model (Upadhyay et al., 2017). Our findings showed that MP1102 displayed synergistic or additive effects with lincomycin, penicillin, and ceftriaxone (FICI $=0.29-0.96$ ) (Figure 1D), which suggests that the use of MP1102 with these drugs might prevent or delay the growth of resistant mutant strains.

Plectasin-derived peptide MP1102 and NZ2114 and the hybrid peptide LHP7 based on plectasin can destroy the cell membrane of Gram-positive bacteria, such as Clostridium perfringens and S. aureus Xi et al., 2014; Zong et al., 2016; Zheng et al., 2017. The in vitro mode action of MP1102 on the $S$. suis cell membrane was first identified in this study. The PI-stained percentages of S. suis CVCC 3928 cells were $34.9-58.2 \%$ after treatment with MP1102 at $1 \times, 2 \times$, and $4 \times$ MIC for $2 \mathrm{~h}$, which suggested that MP1102 could induce $S$. suis cell plasma membrane damage (Figure 1E). Further analysis demonstrated that cell ultrastructure changes were accompanied by deep cell surface shrinkage, intracellular content leakage, heterogeneous electron density in cytoplasm, plasmolysis, the loss of membrane integrity and even complete cell lysis based on SEM and TEM observations (Figure 2). Combined with FACS analysis of MP1102-treated bacteria, the results revealed that the $S$. suis cell membrane was an important target of MP1102.

It has been demonstrated that AMPs have a role in binding with intracellular macromolecules after traversing the cell membrane barrier and translocating into the cytoplasm, causing inhibition of their biological synthesis and functions (Li et al., 2013; Hao et al., 2017). Genomic DNA from S. suis CVCC 3928 was almost completely inhibited by MP1102 at the peptide/DNA mass ratio of 10.0 on the gel (Figure 3A). The result indicated that MP1102 could tightly bind to DNA and block the migration of DNA, which is consistent with that of the peptides, such as melittin, marine arenicin, and bovine lactoferricin (Wei et al., 2016; Hao et al., 2017; Wang et al., 2017). Moreover, CD spectroscopy analyses further confirmed that MP1102 not only binds to S. suis CVCC 3928 genomic DNA but also interacts with $S$. suis genomic DNA, weakening base stacking force and disrupting the DNA helical structure by inserting the base pairs of DNA (Figure 3B). It has been demonstrated that some AMPs can inhibit cellular functions by binding to nucleic acids. For instance, the binding of the antimicrobial lysine-peptoid hybrid LP5 led to inhibition of DNA synthesis and induced an SOS response in $S$. aureus (Gottschalk et al., 2013). The direct interaction of host defense peptide-mimic oligo-acyl-lysyls (OAKs) with bacterial DNA inhibited the process of thymidine incorporation, thus inhibiting biosynthesis and ultimately leading to cell death (Sarig et al., 


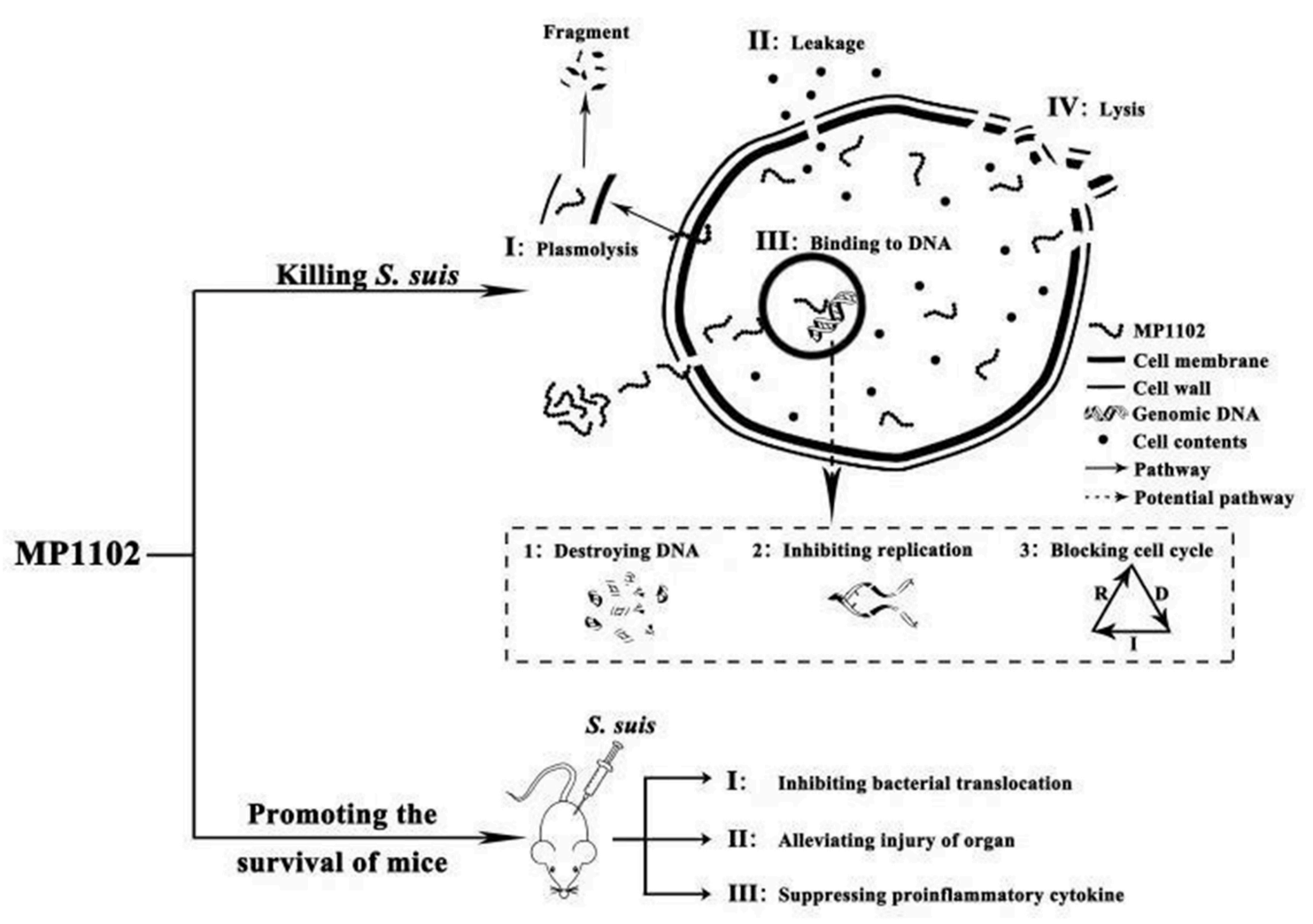

FIGURE 6 | Mode of actions of MP1102 against S. suis in vitro and its action effects on mice challenged with S. suis. In vitro mechanism of MP1102 against S. suis is spatiotemporal. First, the cell membrane of the pathogen was slightly destroyed by MP1102, and the latter penetrated cell membrane and bound to genomic DNA of S. suis, resulting in DNA destruction, inhibition of DNA replication and cell cycle interference. As a result, severe damage of the membrane occurred, causing leakage of cell contents and cell lysis as an irreversibly comprehensive cyto-event. At the same time, in vivo mechanism of MP1102-protected mice challenged with S. suis could be accordingly deduced as inhibition of bacterial translocation, suppression of proinflammatory cytokines and alleviation of organ injury. These events ultimately contributed to improvement of mouse survival.

2011). The in vitro mechanism of MP1102 against S. suis is spatiotemporal. First, cell membrane is slightly destroyed by mechanical or chemical mechanisms. Then, the peptide enters into the cell and binds to genomic DNA of S. suis, which affects DNA replication and interferes with the cell cycle mainly by a biological process (Zong et al., 2016; Zheng et al., 2017). Finally, severe damage to the membrane occurs with the leakage of cell contents, and cell lysis is an irreversibly comprehensive result. This dual mechanism that destroyed cell membrane and interfered with DNA in terms of time and space laid the foundation for low molecular cytology and no drug resistance to MP1102.

In addition, MP1102 demonstrated excellent in vivo activity against $S$. suis in mice in this study (Figures 4, 5) similar to NZ2114 (Jiao et al., 2017). A mass of S. suis CVCC 3928 cells was detected in the liver, lung, spleen, and blood of the untreated group, which caused septicemia and acute death (Lun et al., 2007). A 33.3-50\% increase in survival was noted for MP1102 treatment compared with ceftriaxone (Figure 4A), and MP1102 protected the lung, liver, and spleen from acute injury (Figure 5). A greater reduction of viable bacteria in liver, lung, spleen, and blood was also observed with increasing doses of MP1102 from 2.5 to $5.0 \mathrm{mg} / \mathrm{kg}$ of body weight compared with control mice, which showed a dosedependent effect (Figure 4B). Moreover, MP1102 significantly inhibited the release of proinflammatory cytokines IL-1 $\beta$ and TNF- $\alpha$ in mice challenged with $S$. suis (Figure 4C), but its inhibitory effect on immunosuppressive factor IL-10 was not significant. These findings indicated that MP1102 mainly acted on the immune enhancing factor, thereby reducing the body's inflammatory response to infection. This result is similar to the report of Jiao et al. (2017), in which NZ2114 partly inhibited or regulated the serum concentrations of pro-inflammatory (IL-6 and TNF- $\alpha$ ) and anti-inflammatory cytokines (IL-10). Together, these results suggest that MP1102 has potential to treat S. suis infection.

In conclusion, multiple in vitro and in vivo effects of MP1102 on resistant S. suis CVCC 3928 were studied for the first time. The following results were observed: (I) multiple modes of action of MP1102, including damage to the bacterial cell plasma membrane and interaction with bacterial genomic DNA, were revealed (Figure 6). (II) MP1102 increased the survival ratio of S. suis-infected mice; inhibited bacterial translocation in liver, lung, spleen, and blood; protected the lung, liver, and spleen from 
acute injury; and suppressed the secretion of pro-inflammatory cytokines (IL-1 $\beta$ and TNF- $\alpha$ ) (Figure 6). Therefore, as a novel antimicrobial agent, MP1102 is a promising candidate against multidrug-resistant $S$. suis.

\section{AUTHOR CONTRIBUTIONS}

JW, DT, and HF conceptualized the study and designed the experiments. FZ and NY oversaw the operation of the experiments. FZ, NY, XMW, XW, RM, YH, and ZL conducted the data analysis and created the methodology. FZ and ZL contributed to the visualization. FZ wrote the original draft of the manuscript. JW, DT, and XMW contributed to the writing, review, and editing of the manuscript.

\section{REFERENCES}

Andes, D., Craig, W., Nielsen, L. A., and Kristensen, H. H. (2009). In vivo pharmacodynamics characterization of a novel plectasin antibiotic, NZ2114, in a murine infection model. Antimicrob. Agents. Chemother. 53, 3003-3009. doi: 10.1128/AAC.01584-08

Brinch, K. S., Tulkens, P. M., Van Bambeke, F., Frimodt-Møller, N., Høiby, N., and Kristensen, H. H. (2010). Intracellular activity of the peptide antibiotic NZ2114: studies with Staphylococcus aureus and human THP-1 monocytes, and comparison with daptomycin and vancomycin. J. Antimicrob. Chemother. 65, 1720-1724. doi: 10.1093/jac/dkq159

Callens, B. F., Haesebrouck, F., Maes, D., Butaye, P., Dewulf, J., and Boyen, F. (2013). Clinical resistance and decreased susceptibility in Streptococcus suis isolates from clinically healthy fattening pigs. Microb. Drug. Resist. 19, 146-151. doi: $10.1089 / \mathrm{mdr} .2012 .0131$

Cao, X., Zhang, Y., Mao, R. Y., Teng, D., Wang, X. M., and Wang, J. H. (2015). Design and recombination expression of a novel plectasin-derived peptide MP1106 and its properties against Staphylococcus aureus. Appl. Microbiol. Biotechnol. 99, 2649-2662. doi: 10.1007/s00253-014-6077-9

Clinical and Laboratory Standard Institute (2014). Performance Standard for Antimicrobial Susceptibility Test: Twenty-Four Informational Supplement [S]. CLSI Document M100-S24. Wayne, PA: CLSI.

Dejace, J., Wood, E., and Bagley, P. (2017). Streptococcus suis meningitis can require a prolonged treatment course. Int. J. Infect. Dis. 65, 34-36. doi: 10.1016/j.ijid.2017.09.011

Feng, Y., Zhang, H., Ma, Y., and Gao, G. (2010). Uncovering newly emerging variants of streptococcus suis, an important zoonotic agent. Trends. Microbiol. 18, 124-131. doi: 10.1016/j.tim.2009.12.003

Feng, Y., Zhang, H., Wu, Z., Wang, S., Cao, M., and Hu, D. (2014). Streptococcus suis infection: an emerging/reemerging challenge of bacterial infectious diseases? Virulence 5, 477-497. doi: 10.4161/viru.28595

Ginders, M., Leschnik, M., Künzel, F., Kampner, D., Mikula, C., Steind, G., et al. (2017). Characterization of Streptococcus pneumoniae isolates from Austrian companion animals and horses. Acta Vet. Scand. 59:79. doi: 10.1186/s13028-017-0348-2

Gottschalk, S., Ifrah, D., Lerche, S., Gottlieb, C. T., Cohn, M. T., Hiasa, H., et al. (2013). The antimicrobial lysine-peptoid hybrid LP5 inhibits DNA replication and induces the SOS response in Staphylococcus aureus. BMC Microbiol. 13:192. doi: 10.1186/1471-2180-13-192

Groves, M. D., Jordan, D., Chapman, T. A., and Jassim, R. (2015). Multilocus sequence typing of Australian Streptococcus suis type 2 by MALDI-TOF mass spectrometry analysis of PCR amplicons. Vet. Microbiol. 177, 394-397. doi: 10.1016/j.vetmic.2015.03.006

Hao, Y., Yang, N., Wang, X. M., Teng, D., Mao, R. Y., Wang, X., et al. (2017). Killing of Staphylococcus aureus and Salmonella enteritidis and neutralization of lipopolysaccharide by 17-residue bovine lactoferricins: improved activity of Trp/Ala-containing molecules. Sci. Rep. 7:44278. doi: 10.1038/srep44278

\section{FUNDING}

This study was supported by the National Innovation Program of Agricultural Science and Technology in CAAS (CAAS-ZDXT2018008 and CAAS-ASTIP-2013-FRI-02) and National Natural Science Foundation of China (No. 31572445, 31572444, 31672456).

\section{ACKNOWLEDGMENTS}

We acknowledge Tong Zhao and Jingnan Liang from the Core Facility at the Institute of Microbiology at the Chinese Academy of Sciences (CAS) for their technical support with the flow cytometric SEM and TEM analyses.

Hodges, T. L., Zighelboimdaum, S., Eliopoulos, G. M., Wennersten, C., and Moellering, R. C. (1992). Antimicrobial susceptibility changes in Enterococcus faecalis following various penicillin exposure regimens. Antimicrob. Agents. Chemother. 36,121-125. doi: 10.1128/AAC.36.1.121

Hughes, J. M., Wilson, M. E., Wertheim, F. L., Trung, H. D., Taylor, N. W., and Schultsz, C. (2009). Streptococcus suis: an emerging human pathogen. Clin. Infect. Dis. 48, 617-625. doi: 10.1086/596763

Jiao, J., Mao, R. Y., Teng, D., Wang, X., Hao, Y., Yang, N., et al. (2017). In vitro and in vivo antibacterial effect of NZ2114 against Streptococcus suis type 2 infection in mice peritonitis models. AMB Express 7:44. doi: 10.1186/s13568-0170347-8

Jiao, J., Mao, R. Y., Wang, X. M., Zhang, Y., Teng, D., Feng, X. J., et al. (2015). GAPinitiated constitutive expression of a novel plectasin-derived peptide MP1106 by Pichia pastoris and its activity against Streptococcus suis. Process Biochem. 50, 253-261. doi: 10.1016/j.procbio.2014.12.019

Kilkenny, C., Browne, W. J., Cuthill, I. C., Emerson, M., and Altman, D. G. (2010). Improving bioscience research reporting: the ARRIVE guidelines for reporting animal research. PLoS Biol. 8:e1000412. doi: 10.1371/journal.pbio.10 00412

Knodell, R. G., Ishak, K. G., Black, W. C., Chen, T. S., Craig, R., Kaplowitz, N., et al. (1981). Formulation and application of a numerical scoring system for assessing histological activity in asymptomatic chronic active hepatitis. Hepatology 1, 431-435. doi: 10.1002/hep.18400 10511

Kock, C., Beineke, A., Seitz, M., Ganter, M., Waldmann, K. H., ValentinWeigand, P., et al. (2009). Intranasal immunization with a live Streptococcus suis isogenic ofs mutant elicited suilysin-neutralization titers but failed to induce opsonizing antibodies and protection. Vet. Immunol. Immunopathol. 132, 135-145. doi: 10.1016/j.vetimm.2009.05.009

Li, L., Shi, Y., Cheserek, M. J., Su, G., and Le, G. (2013). Antibacterial activity and dual mechanisms of peptide analog derived from cell-penetrating peptide against Salmonella typhimurium and Streptococcus pyogenes. Appl. Microbiol. Biotechnol. 97, 1711-1723. doi: 10.1007/s00253-012-4352-1

Li, Z., Mao, R., Teng, D., Hao, Y., Chen, H., Wang, X., et al. (2017). Antibacterial and immunomodulatory activities of insect defensins-DLP2 and DLP4 against multidrug-resistant Staphylococcus aureus. Sci. Rep. 7:12124. doi: 10.1038/s41598-017-10839-4

Lun, Z., Wang, Q., Chen, X., Li, A., and Zhu, X. (2007). Streptococcus suis: an emerging zoonotic pathogen. Lancet. Infect. Dis. 7, 201-209. doi: 10.1016/S1473-3099(07)70001-4

Lynch, J. P., and Zhanel, G. G. (2010). Streptococcus pneumoniae: epidemiology and risk factors, evolution of antimicrobial resistance, and impact of vaccines. Curr. Opin. Pulm. Med. 16:217-225. doi: 10.1097/MCP.0b013e3283 385653

Mah, T. F., Pitts, B., Pellock, B., Walker, G. C., Stewart, P. S., and O’Toole, G. A. (2003). A genetic basis for Pseudomonas aeruginosa biofilm antibiotic resistance. Nature 426, 306-310. doi: 10.1038/nature02122 
Michaud, S., Duperval, R., and Higgins, R. (2016). Streptococcus suis meningitis: first case reported in Quebec. Can. J. Infect. Dis. 7, 329-331. doi: $10.1155 / 1996 / 354693$

Mygind, P. H., Fischer, R. L., Schnorr, K. M., Hansen, M. T., Sönksen, C. P., Ludvigsen, S., et al. (2005). Plectasin is a peptide antibiotic with therapeutic potential from a saprophytic fungus. Nature. 437, 975-980. doi: 10.1038 /nature04051

Osterberg, L., and Blaschke, T. (2005). Adherence to medication. N. Engl. J. Med. 353, 487-497. doi: 10.1056/NEJMra050100

Ostergaard, C., Sandvang, D., Frimodt-Moller, N., and Kristensen, H. H. (2009). High Cerebrospinal fluid (CSF) penetration and potent bactericidal activity in CSF of NZ2114, a novel plectasin variant, during experimental pneumococcal meningitis. Antimicrob. Agents. Chemother. 53, 1581-1585. doi: 10.1128/AAC.01202-08

Rotta, A. T., Gunnarsson, B., Hernan, L. J., Fuhrman, B. P., and Steinhorn, D. M. (1999). Partial liquid ventilation influences pulmonary histopathology in an animal model of acute lung injury. J. Crit. Care. 14, 84-92. doi: 10.1016/S0883-9441(99)90019-9

Sahl, H. G., and Shai, Y. (2015). Bacterial resistance to antimicrobial peptides. Biochimica. Et. Biophysica. Acta 1848, 3019-3025. doi: 10.1016/j.bbamem.2015.08.009

Sarig, H., Goldfeder, Y., Rotem, S., and Mor, A. (2011). Mechanisms mediating bactericidal properties and conditions that enhance the potency of a broad-spectrum oligo-acyl-lysyl. Antimicrob. Agents Chemother. 55, 688-695. doi: 10.1128/AAC.00666-10

Seele, J., Hillermann, L. M., Beineke, A., Seitz, M., von Pawel-Rammingen, U., Valentin-Weigand, P., et al. (2015). The immunoglobulin M-degrading enzyme of Streptococcus suis, IdeSsuis, is a highly protective antigen against serotype 2 . Vaccine 33, 2207-2212. doi: 10.1016/j.vaccine.2015.03.047

Segura, M. (2015). Streptococcus suis vaccines: candidate antigens and progress. Expert. Rev. Vaccines 14, 1-11. doi: 10.1586/14760584.2015.11 01349

Spiss, H., Kofler, M., Hausdorfer, H., Pfausler, B., and Schmutzhard, E. (1999). Streptococcus suis meningitis and neurophysiology of the acoustic system. First case report from Austria. Nervenarzt 70, 738-741. doi: 10.1007/s0011500 50503

Upadhyay, K., Hiregoudar, B., Meals, E., English, B. K., and Talati, A. J. (2017). Combination therapy with ampicillin and azithromycin improved outcomes in a mouse model of group B Streptococcal sepsis. PLoS ONE 12:e182023. doi: 10.1371/journal.pone.0182023

van der Poll, T., and Opal, S. M. (2009). Pathogenesis, treatment, and prevention of pneumococcal pneumonia. Lancet 374, 1543-1556. doi: 10.1016/S0140-6736(09)61114-4

Varela, N. P., Gadbois, P., Thibault, C., Gottschalk, M., and Wilson, P. (2013). Antimicrobial resistance and prudent drug use for Streptococcus suis. Anim. Health. Res. Rev. 14, 68-77. doi: 10.1017/S1466252313000029

Vilaichone, R. K., Mahachai, V., and Nunthapisud, P. (2000). Streptococcus suis peritonitis: case report. J. Med. Assoc. Thai. 83, 1274-1277.

Wang, X., Teng, D., Mao, R., Yang, N., Hao, Y., and Wang, J. (2017). Combined systems approaches reveal a multistage mode of action of a marine antimicrobial peptide against pathogenic Escherichia coli and its protective effect against bacterial peritonitis and endotoxemia. Antimicrob. Agents. Chemother. 61, e01056-e01016. doi: 10.1128/AAC.01056-16

Wei, S., Li, C., Man, L., Zong, X., Han, D., and Chen, Y. (2016). Antimicrobial peptide melittin against Xanthomonas oryzae pv. oryzae, the bacterial leaf blight pathogen in rice. Appl. Microbiol. Biotechnol. 100, 5059-5067. doi: 10.1007/s00253-016-7400-4

Wisselink, H. J., Vecht, U., Stockhofe-Zurwieden, N., and Smith, H. E. (2001). Protection of pigs against challenge with virulent Streptococcus suis serotype 2 strains by a muramidase-released protein and extracellular factor vaccine. Vet. Rec. 48, 473-477. doi: 10.1136/vr.148.15.473

Xi, D., Teng, D., Wang, X. M., Mao, R. Y., Yang, Y. L., Xiang, W. S., et al. (2013). Design, expression and characterization of the hybrid antimicrobial peptide LHP7, connected by a flexible linker, against Staphylococcus and Streptococcus. Process Biochem. 48, 453-461. doi: 10.1016/j.procbio.2013.01.008

Xi, D., Wang, X. M., Teng, D., Mao, R. Y., Zhang, Y., Wang, X. J., et al. (2014). Mechanism of action of the tri-hybrid antimicrobial peptide LHP7 from lactoferricin, HP and plectasin on Staphylococcus aureus. BioMetals 27, 957-968. doi: 10.1007/s10534-014-9768-x

Xiong, Y. Q., Hady, W. A., Deslandes, A., Rey, A., Fraisse, L., Kristensen, H. H., et al. (2011). Efficacy of NZ2114, a novel plectasin-derived cationic antimicrobial peptide antibiotic, in experimental endocarditis due to methicillin-resistant Staphylococcus aureus. Antimicrob. Agents. Chemother. 55, 5325-5330. doi: 10.1128/AAC.00453-11

Yang, N., Wang, X. M., Teng, D., Mao, R. Y., Hao, Y., Zong, L. F., et al. (2016). Modification and characterization of a new recombinant marine antimicrobial peptide N2. Process Biochem. 51, 734-739. doi: 10.1016/j.procbio.2016.03.005

Yu, H., Jing, H., Chen, Z., Zheng, H., Zhu, X., and Wang, H. (2006). Human Streptococcus suis outbreak, Sichuan, China. Emerg. Infect. Dis. 12, 914-920. doi: 10.3201/eid1206.051194

Zanen, H., and Engel, H. (1975). Porcine streptococci causing meningitis and septicaemia in man. Lancet 1, 1286-1288. doi: 10.1016/S0140-6736(75)92563-5

Zhang, J., Yang, Y., Teng, D., Tian, Z., Wang, S., and Wang, J. (2010). Expression of plectasin in Pichia pastoris and its characterization as a new antimicrobial peptide against Staphyloccocus and Streptococcus. Protein Express Purif. 78,189-196. doi: 10.1016/j.pep.2011.04.014

Zhang, Y., Teng, D., Wang, X., Mao, R., Cao, X., Hu, X., et al. (2015). In vitro and in vivo characterization of a new recombinant antimicrobial peptide, MP1102, against methicillin-resistant Staphylococcus aureus. Appl. Microbiol. Biotechnol. 99, 6255-6266. doi: 10.1007/s00253-015-6394-7

Zheng, X., Wang, X., Teng, D., Mao, R., Hao, Y., Yang, N., et al. (2017). Mode of action of plectasin-derived peptides against gas gangreneassociated Clostridium perfringens type A. PLoS ONE 12:e0185215. doi: 10.1371/journal.pone.0185215

Zong, L., Teng, D., Wang, X., Mao, R., Yang, N., Hao, Y., et al. (2016). Mechanism of action of a novel recombinant peptide, MP1102, against Clostridium perfringens, type C. Appl. Microbiol. Biotechnol. 100, 5045-5057. doi: $10.1007 / \mathrm{s} 00253-016-7387-\mathrm{x}$

Conflict of Interest Statement: The authors declare that the research was conducted in the absence of any commercial or financial relationships that could be construed as a potential conflict of interest.

Copyright (c) 2019 Zhao, Yang, Wang, Mao, Hao, Li, Wang, Teng, Fan and Wang. This is an open-access article distributed under the terms of the Creative Commons Attribution License (CC BY). The use, distribution or reproduction in other forums is permitted, provided the original author(s) and the copyright owner(s) are credited and that the original publication in this journal is cited, in accordance with accepted academic practice. No use, distribution or reproduction is permitted which does not comply with these terms. 